MYOCARDIAL BLOOD FLOW (q) AND OXYGEN CONSUMPTION $\left(\hat{v}_{\mathrm{O}_{2}}\right)$

211 TONICALEY INSTRUMENTED LAMBS WITH AN AORTO-

PULMONARY SHUNT (S). Paul G. Toorop, Rudy Hardjowijono, Jan H. Koers, Michiel Dalinghaus, Jaap R.G. Kuipers. Depts of Pediatrics and Thoracic Surgery, University Hospital, Groningen, The Netherlands (Spon. by A.M. Rudolph)

We showed that heart rate (HR) in lambs with a $S$ is higher than in those without a $S$. This increase will affect myocardial $\hat{\nabla}_{\mathrm{O} 2}$. We studied myocardial $q$ and left ventricular (LV) $\nabla_{\mathrm{O} 2}$ in 7 lambs with a $S$ (aged $7+1$ wks, mean+SEM). 4-14 days prior to the studies we inserted catheters into aorta (Ao), coronary sinus (CS) and left atrium, and a Goretex $\mathbb{B}$ graft between descencing Ao and pulmonary artery (PA). Electromagnetic flow probes (EFP) were placed around AO and PA to measure pulmonary $\left(\mathrm{q}_{\mathrm{p}}\right)$ and systemic placed around $A O$ and $P A$ to measure pulmonary $\left(q_{p}\right)$ and systemic
$\left(q_{s}\right)$ blood flows, respectively. As controls another 8 lambs (aged $7 \pm 1$ wks) were instrumented in the same way except for the Goretex $B$ graft and PA EFP. Myocardial $q$ of LV was calculated by the radioactive microsphere method. $\mathrm{LV} \hat{\nabla}_{\mathrm{O} 2}$ was calculated from myocardial $q$ of $\mathrm{LV}$ and the difference in $\mathrm{O}_{2}$ content between $A O$ and CS blood. The $q_{p}: q_{s}$ ratio of the $S$ lambs was 2.3 . The $S$ lambs had a higher $\mathrm{HR}(151+6$ vs $110+7, \mathrm{p}<0.001)$, myocardial $\mathrm{q}$ of $\mathrm{LV}$ $(241+26$ vs $136+17 \mathrm{ml} / \mathrm{min} / 100 \overline{\mathrm{gLV}}, \mathrm{p}<0.005), \mathrm{LV} \hat{\nabla}_{\mathrm{O} 2}(757 \pm 74 \mathrm{vs}$ $(241+26$ vs $136+17 \mathrm{ml} / \mathrm{min} / 100 \mathrm{gLV}, \mathrm{p}<0.005), \mathrm{LV} \mathrm{V}_{\mathrm{O} 2}(757 \pm 74 \mathrm{vs}$
$405+35 \mu \mathrm{mol} / \mathrm{min} / 100 \mathrm{gLV}, \mathrm{p}<0.001)$, and a higher total heart weight $(108.2 \pm 12.0$ vs $77.3+6.9 \mathrm{gr}, \mathrm{p}<0.05)$ than the control lambs. Peak Ao pressure and $q_{s}$ were not significantly different in the two groups. These findings suggest that the increase in HR in the $\mathrm{S}$ lambs may be the main reason for the increase in LV $\hat{\nabla}_{\mathrm{O} 2}$.

212 IMPERFECTA (OI). Petros Tsipouras, Jay Shapiro, John School, Piscataway, $\mathrm{NJ}$; McGill University, Montreal; Children's Hospital; Clinical Center and NHLBI, NIH, Bethesda; Harvard University, Cambridge, MA: (sponsored by A.Sadeghi-Nejad) The prevalence of ab in 112 subjects with OI at two centers (MCH and $\mathrm{N}$ (H). The groups differed in the numbers of families and NIH). The groups difiect from 12 families, NIH $22 / 47$ subjects included: MCH from 9 families.

normal population, except fnx \% fraction
W. et al, Circulation 62: 1054,1980 ).

\begin{tabular}{|c|c|c|c|c|c|c|c|}
\hline Group & MC & & & $\mathrm{NI}$ & [H & $\mathrm{MCH}$ & NIH \\
\hline observation & $\pi$ & S.E. & A & $\bar{x}$ & S.E. & B & $B$ \\
\hline Aorta & 114.6 & 1.8765 & $\mathrm{P}=\langle .01$ & 107.3 & $1.64 \quad 47$ & $\mathrm{P}=\langle .01$ & $P=<.01$ \\
\hline LA diameter & 89.4 & 1.6153 & - & 90.7 & 1.7647 & $<01$ & $<.01$ \\
\hline LV diameter 1 & 104.4 & $1.66 \quad 28$ & - & 104.5 & $1.63 \quad 41$ & $<.05$ & $<.05$ \\
\hline $\mathrm{V}_{\mathrm{PW}}$ & 89.1 & $2.54 \quad 24$ & $<.01$ & 97.8 & $2.61 \quad 43$ & $<.01$ & NS \\
\hline Septum & 87.0 & $\begin{array}{ll}3.12 & 30\end{array}$ & $<.05$ & 94.5 & $2.37 \quad 43$ & $<.01$ & $<.01$ \\
\hline$\% \mathrm{fs}(.28-.40)$ & 0.17 & $0.03 \quad 30$ & $<.01$ & 0.29 & $0.02 \quad 43$ & $<.01$ & $<.01$ \\
\hline
\end{tabular}

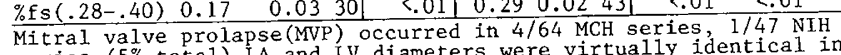
series (5\% tota1) LA and LV diameters were virtualiy ificantly the two groups, yet all other measurements were significanth different between them (column A). Except for ${ }_{P W}$, Norm (column B). groups differed significantly from the expecties than expected Aortic dilatation was more frequent with famliles than expected due to chance(P<.01). Thus, decreased wall thickness and aor. MVP is not increased above the expected norm.

\section{EVALUATION FOR PDA IN PRETERM INFANTS \\ 213 UTILIZING 7.5 MEGAHERTZ 2-D BCHOCARDIOGRAPHY}

G. Wesley Vick, III, James C. Huhta. Spon. by Paul C. Gillette. Baylor College of Medicine and Texas Children's Hospital, The Lillie Frank Abercrombie Section of Cardiology, Dept. of Pediatrics, Houston, TX.

Evaluation for patent ductus arteriosus (PDA) by both Doppler examination and direct two-dimensional (2-D) echocardiographic visualization has been reported in term infants and children. However, visualization of a PDA in preterm infants with lung disease has been more difficult. Utilizing a recently developed $7.5 \mathrm{MHz}$ mechanical more difficult. Utilizing a recently developed scanner with interfaced 2-D directed pulsed Doppler we evaluated our initial experience in 14 premature infants with lung disease. Doppler sampling was performed at the pulmonary end of the ductus arteriosus from a suprasternal approach. Patients ranged in age from 1 day to 30 diys (mean 11 days) and from 510 to 2300 grams in weight (mean 1015 grams). Imaging of the ductus arteriosus was successful in 13/14 (93\%). Doppler evaluation of flow in the main pulmonary artery and descending aorta was successful in all. In 8 infants the DA was closed by both 2-D echo and Doppler exam infants the DA was closed by both 2-D echo and Doppler exam (excluded by retrograde aortography in 2). In 5 infants a PDA was
present by both methods. In 1 infant the DA was patent by Doppler exam but could not be imaged adequately by 2-D echo. This markedly improved inaging capability should allow longitudinal noninvasive studies of PDA morphology in premature infants with lung disease.
214 DYSFUNCTION IN THE NEONATE. Lota Viray, Bijan Siassi, Mea. Ctr., Dept of Ped., Los Angeles.

Severe perinatal asphyxia is associated with myocardial dysfunction in the neonate, however, the contributory roles of hypoglycemia and hypocalcemia is less clear. Serum glucose, total and ionized $\mathrm{Cat+}$ and $\mathrm{oH}$ were measured at $0,1,4,24$ and 48 hours in 10 term asphyxiated infants ( $\mathrm{BW}=3381 \pm 772 \mathrm{~g}, \mathrm{GA}=40 \pm 1.5$ wks $)$. Mmode echocardiograms and serum total creatine phosphokinase (CPK) and $\mathrm{CPK}$ isoenzymes were measured during the first 8,24 , and 48 hours of life. All neonates had fetal distress as evidenced by severe variable or late decelexations in their fetal heart rate tracing. Eight infants required emergency c-section. One minute Apgar scores in all infants were $<3$. Significant left ventricular (LV) dysfunction was diagnosed in the presence of abnormalities in at least 2 of the following 3 echocardiographic findings: left atrial/aortic ratio $>1.3$, LV pre-ejection period/ $\mathrm{LV}$ ejection time ratio $>0.42$ and the $\mathrm{LV}$ shortening fraction 0.28 . Four neonates had evidence of LV dysfunction. The MB fraction of $\mathrm{CPK}$ isoenzymes was elevated to a greater extent in these 4 infants. Three of the 4 infants with and only one of the 6 without LV dysfunction had hypoglycemia. Serum ionized Ca+t remained normal in all 10 infants. Conclusion: 1) Hypoglycemia significantly contributes to asphyxial myocardial dysfunction; 2) Hypocalcemia is not a significant contributing factor 3) Serial measurement of $M$-mode and MB fraction of CPK isoenzymes identifies asphyxiated neonates with significant myocardial dysfunction.

EFFECT OF ADENOSINE ON CEREBRAL METABOLIC 215 RATE FOR O2 (CMRO2) AND CEREBRAL BLOOD FLOW Belik, ${ }^{*}$ and Maria Delivoria-Papadopoulos. University of Pennsylvania, Depts. of Physiolology and Pediatrics, Phila., PA.

Previous studies suggest that adenosine released by tissue may mediate local vasodilation and thus couple local flow to the $\mathrm{O}_{2}$ requirements of the tissue. The present experiments examine the relationship between $\mathrm{CMRO}_{2}$ and $\mathrm{CBF}$ in newborn lambs during infusion of adenosine. A total of 17 lambs were divided into two groups. In Group $I(n=7)$ intracarotid infusion of adenosine concentrations of $0.06,0.12$, and $0.24 \mathrm{mg} / \mathrm{kg} / \mathrm{min}$ increased CBF by 35,114 , and $102 \%$, respectively, suggesting that maximal adenosine effects were attained with 0.12 and $0.24 \mathrm{mg} / \mathrm{kg} / \mathrm{min}$. In Group II $(n=10) \mathrm{CBF}$ and $\mathrm{CMRO}_{2}$ were determined during infusion $0.24 \mathrm{mg} / \mathrm{kg} / \mathrm{min}$ adenosine. Of these, 5 served as controls, studied unanesthetized $\left(\mathrm{CMRO}_{2}=5.02 \mathrm{ml} / \mathrm{min} / 100 \mathrm{~g}\right)$, and 5 were studied anesthetized (alpha-chloralosel to reduce $\mathrm{CMRO}_{2}$ to 2.20 $\mathrm{ml} / \mathrm{min} / 100 \mathrm{~g}$. In the anesthetized group CBF was decreased to $37 \pm 3$ $\mathrm{ml} / \mathrm{min} / 100 \mathrm{~g}$ compared to the control group ( $\mathrm{CBF}=87 \pm 7 \mathrm{ml} / \mathrm{min} / 100 \mathrm{~g}$ ). Adenosine increased $\mathrm{CBF}$ by $113 \%$ and $80 \%$ in the control and anesthetized lambs respectively. Cerebrovascular resistance was $0.84 \pm 0.08$ and $2.48 \pm 0.25 \mathrm{mmHg} / \mathrm{ml} / \mathrm{min} / 100 \mathrm{~g}$ in the control and anesthetized groups respectively and decreased by $56 \%$ and $58 \%$ during adenosine infusion. In spite of the concentration of adenosine infused, $\mathrm{CBF}$ was less in the anesthetized lambs as a function of the level of CMRO Since adenosine action on smooth muscle is receptor mediated, these data would suggest that the relationship between $C B F$ and $C_{2} M_{2}$ is intact when adenosine receptors may be saturated.

MYOCARDIAL GLYCOGEN METABOLISM IS MODIFIED DURING

216 CHRONIC HYPERGLYCEMIA AND HYPERINSULINEMIA IN THE FETAL LAMB. David Warburton. (Spon. by T.G. Keens) Neonatal-Respiratory Disease Division, Childrens Hospital of Los Angeles, Dept. Pediatrics, University of Southern California School of Medicine, Los Angeles.

I studied the developmental profile of glycogen, glycogen synthase and phosphorylase in myocardia of control fetal lambs at 123, 131, and 142d gestation (term 150d) and in the myocardia of their twins treated with intravenous glucose $(16 \pm 2$ $\mathrm{mg} / \mathrm{kg} / \mathrm{min}, \mathrm{M} \pm \mathrm{SE})$ from $112 \mathrm{~d}$ onwards. Serum glucose $(34 \pm 2 \mathrm{mg} / \mathrm{dl})$ and insul in $47 \pm 11, \mathrm{U} / \mathrm{ml}$ ) were higher in the glucose treated fetuses than serum glucose $(19 \pm 3 \mathrm{mg} / \mathrm{dl}, \mathrm{P}<0.01)$ and insulin fetuses than serum glucose $(19 \pm 3 \mathrm{mg} / \mathrm{d})$
$(14 \pm 2 \mathrm{HU} / \mathrm{ml}, P<0.01)$ in the controls.

Glycogen content $\mu \mathrm{g} / \mathrm{mg}$ wet $w \mathrm{t}$ Synthase a Nmole/min/mg prot Synthase $a+b$ Nmole/min/mg prot Phosphorylase a Nmole/min/mg prot Phosphorylase a $a$ Phosphorylase $a+b$
Nmole/min/mg prot

$\begin{array}{rrr}\frac{123 \mathrm{~d}}{117} & \frac{131 \mathrm{~d}}{60} & \frac{142 \mathrm{~d}}{74} \\ 138 & 319 & 78 \\ 1.0 & 2.5 & 1.6 \\ 1.3 & 2.1 & 2.7 \\ 6.7 & 9.2 & 6.6 \\ 7.4 & 12.1 & 7.9 \\ 2.0 & 1.1 & 0.7 \\ 0.9 & 1.1 & 0.6 \\ 13.6 & 15.5 & 12.1 \\ 10.6 & 17.3 & 10.4\end{array}$

Control Glucose Control Control Control Glucose Glucose Glucose Glucose

Myocardial glycogen was increased 1.2 fold at 123d gestation and 5.0 fold at 131d gestation in the glucose treated fetuses. Enzyme activities were also modified by chronic hyperglycemia. 